\title{
Antimicrobials in Future Caries Control?
}

\author{
A Review with Special Reference to Chlorhexidine Treatment
}

\author{
Svante Twetman \\ Department of Odontology, Pediatric Dentistry, Umeå University, Umeå, Sweden
}

\section{Key Words}

Antimicrobials $\cdot$ Chlorhexidine $\cdot$ Clinical trials $\cdot$ Caries prevention

\begin{abstract}
The aim of this paper was to examine recent evidence for the effect of the antibacterial approach to prevent and control caries with special reference to the use of chlorhexidine (CHX). Existing information from the mid 1990s provided limited evidence for the effectiveness of $\mathrm{CHX}$ gels, rinses and toothpaste in preventing caries in permanent teeth of children and adolescents. An updated literature search on $\mathrm{CHX}$ intervention in controlled clinical trials from 1995 to May 2003 unveiled 22 studies covering over 4,500 patients with clinical caries as end point. The vast majority $(n=21$ ) were dealing with $\mathrm{CHX}$-containing varnishes. Since the studies exhibited disparities in design, diagnosis and intervention, the findings were subgrouped with respect to caries type and localization. According to the ranking system of the Swedish Council on Technology Assessment in Health Care, the evidence for an anticaries effect of $\mathrm{CHX}$ varnishes was rated as inconclusive for caries-active schoolchildren and adolescents with regular fluoride exposure. Regarding fissure
\end{abstract}

Paper presented at the ORCA Anniversary Symposium in Konstanz, Germany, 2003.

\section{KARGER}

Fax +41613061234

E-Mail karger@karger.ch

www.karger.com
(C) 2004 S. Karger AG, Basel

0008-6568/04/0383-0223\$21.00/0

Accessible online at: www. karger.com/cre caries, a preventive effect of $\mathrm{CHX}$ varnishes was demonstrated in 4 studies out of 5 when compared to no treatment in children with low fluoride exposure. The evidence for arresting root caries in dry-mouth patients and frail elderly subjects was inconclusive. In conclusion, the evidence from the recent literature was inconclusive for the use of $\mathrm{CHX}$ varnishes for caries prevention in risk groups.

Copyright $@ 2004$ S. Karger AG, Basel

It is generally understood that dental caries is an infectious disease of bacterial origin [van Houte, 1994] and, therefore, it must be considered relevant to utilize an antimicrobial approach to prevent and control the disease. The ultimate goal of antimicrobial therapy is to achieve a shift from an ecologically unfavourable to an ecologically stable biofilm [Marsh, 1994, 2003]. By suppressing the proportion of acidogenic and aciduric bacteria that have a growth advantage in low $\mathrm{pH}$ conditions, less acid is formed in the aqueous interphase between plaque and enamel, which enables and enhances remineralization by fluoride [ten Cate, 1999]. A wide range of antibacterial agents and products, including fluoride and sugar substitutes, are commonly used in preventive dentistry, and numerous in vitro and in vivo reports are available on their influence on bacterial growth and metabolism. This paper is focused on the 'traditional' antiseptic

Dr. S. Twetman

Department of Odontology, Pediatric Dentistry

Medical and Odontological Faculty, Umeå University

SE-901 87 Umeå (Sweden)

Tel. +4690785 6230, Fax +4690770 330, E-Mail svante.twetman@odont.umu.se 
agents and restricted to studies measuring clinical caries as end point. This standpoint may be justified by two main reasons. Firstly, recent findings indicate that surrogate end points, such as the effect of an antimicrobial agent on levels of mutans streptococci (MS) or plaque reduction may not always correlate with eventual caries reduction [Caufield and Dasanayake, 2001; Dasanayake et al., 2002; Anderson, 2003]. Secondly, the really important outcome from the patient's and dentist's perspective is proven reductions in caries. There seems to be consensus over the current indications for a chemotherapeutic approach for caries prevention, limiting its use to cariesactive individuals and to subjects with an increased caries risk and ongoing caries activity [Kidd, 1991; Emilson, 1994; Rozier, 2001]. The aim of this paper was to review and discuss evidence for the efficacy of the antimicrobial approach to prevent dental caries and to identify questions of interest for future research.

\section{Existing Information}

It is generally accepted that chlorhexidine digluconate (CHX) remains the gold standard as antiplaque and antigingivitis agent [Matthijs and Adriaens, 2002]. Although CHX has substantial antimicrobial properties against caries-causing bacteria, its use as anticaries agent remains more controversial. The efficacy in caries prevention has been established in several clinical trials as thoroughly reviewed by Emilson [1994]. It was concluded that CHX gel administered in trays was the most effective regimen and that the outcome of the treatment should be monitored by follow-up bacterial samplings. A meta-analysis by van Rijkom et al. [1996] including 8 clinical trials performed between 1975 and 1994 with gels, rinses and toothpaste in schoolchildren and adolescents at risk $(\mathrm{n}=$ 612) revealed a prevented fraction of $46 \%$ (95\% confidence interval 35-57\%). This meta-analysis was however mostly based on studies conducted two decades ago in study populations with a higher caries prevalence than today, some were of short duration and some lacked a true control group. It was therefore justified to update the literature search for recent randomized (RCT) or controlled clinical trials (CCT) with $\mathrm{CHX}$ rinse, gel or varnish as main intervention with and without additional use of fluoride. The search terms were 'caries', 'chlorhexidine', 'chlorhexidine rinsing', 'gel', 'varnishes' and 'antibacterial treatment', and only papers published in English were considered. The outcome measure was limited to the incidence or progression/regression of manifest and incipient caries lesions on crowns and roots as diagnosed by visual inspection, probing and/or radiographs. Furthermore, interim reports or double publications were excluded. The PubMed (US National Library of Medicine) database disclosed 22 papers published from 1995 to May 2003 in which the efficacy of CHX-containing varnishes and rinses in over 4,500 subjects of various ages was investigated (tables 1 and 2). An immediate reflection was that no studies employing CHX gel with caries as end point seemed to have been performed in recent years. The selected papers were reviewed and subgrouped with respect to caries localization and type. The level of evidence was judged in 4 grades according to the protocol of the Swedish Council on Technology Assessment in Health Care [Britton, 2000; www.sbu.se]: 1 = strong evidence, requiring at least 2 studies with a high level of evidence (A) or a good systematic review; 2 = moderate evidence, requiring 1 study with level $A$ and at least 2 studies with a moderate level of evidence (B); $3=$ limited evidence, requiring at least 2 studies with level $\mathrm{B} ; 4=$ inconclusive evidence, less than 2 studies with level B.

\section{All Tooth Surfaces}

Three recent studies regarding CHX-containing varnish and caries increment in the young permanent dentition of risk and caries-active subjects were found [Forgie et al., 2000; Splieth et al., 2000; de Soet et al., 2002]. In an RCT with more than 1,200 Scottish schoolchildren selected at risk based on past caries experience and high salivary MS levels, Forgie et al. [2000] failed to demonstrate any reduction in caries increment over a 3-year period when a $10 \%$ CHX varnish or a placebo varnish was applied 6-12 times. The applications were initially frequent but reduced by time, which to some extent could explain the lack of efficacy. In the second study, Splieth et al. [2000] selected caries-active schoolchildren that had developed more than 1 new lesion per year for the past years for a treatment combination of CHX varnish and fluoride gel versus fluoride gel controls. Although the experimental group developed less caries over 12 months, the difference was not statistically significant. The study was however small, and larger experimental groups and prolonged study duration would have increased the power of this setting. The third study was performed in a high caries community (Surinam) with semi-annual CHX varnish applications [de Soet et al., 2002], and, again, no effect on caries increment in schoolchildren was demonstrated. On the contrary, it was speculated that a high carbohydrate intake in combination with the CHX treatments could even be detrimental for caries development. 
Table 1. Summary of studies identified between 1995 and May 2003 with CHX varnish intervention and clinical caries outcome

\begin{tabular}{|c|c|c|c|c|c|c|c|c|c|c|c|}
\hline Authors & $\begin{array}{l}\text { Mate- } \\
\text { rial }\end{array}$ & $\begin{array}{l}\text { Age } \\
\text { years }\end{array}$ & Risk & Design & $\begin{array}{l}\text { Inter- } \\
\text { vention }\end{array}$ & Control & $\begin{array}{l}\text { Duration } \\
\text { years }\end{array}$ & $\begin{array}{l}\text { Drop- } \\
\text { out, } \%\end{array}$ & Diagnosis & Outcome & Statistics \\
\hline \multicolumn{12}{|l|}{ Young permanent dentition } \\
\hline Forgie et al. [2000] & 1,240 & $11-13$ & $\geq 10^{5} \mathrm{CFU}$ & $\mathrm{RCT}, \mathrm{DB}$ & 1 & placebo & 3 & 16 & clin. + BW & 6.8/6.4 DMFS & n.s. \\
\hline De Soet et al. [2002] & 238 & $13-14$ & $\begin{array}{l}\text { high-caries } \\
\text { population }\end{array}$ & RCT, DB & 3 & neutral gel & 2.5 & 19 & clin. & 2.1/1.7 DMFS & n.s. \\
\hline Splieth et al. [2000] & 56 & $8-10$ & $>1$ DMFS/year & $\mathrm{CCT}, \mathrm{SB}$ & $2+F g$ & $\mathrm{Fg}$ & 1 & 4 & clin. & 1.2/2.1 DMFS & n.s. \\
\hline \multicolumn{12}{|l|}{ Proximal sites } \\
\hline $\begin{array}{l}\text { Haukali and Poulsen } \\
\text { [2003] }\end{array}$ & 85 & 8 & $\begin{array}{l}\geq 1 \text { proximal } \\
\text { lesion }\end{array}$ & split, DB & 2 & placebo & 2 & 14 & BW & $\begin{array}{l}\text { difference } \\
-0.21\end{array}$ & n.s. \\
\hline Petersson et al. [1998] & 219 & 12 & $\begin{array}{l}\geq 1 \text { proximal } \\
\text { lesion }\end{array}$ & $\mathrm{CCT}, \mathrm{SB}$ & $2+F v$ & $\mathrm{Fv}$ & 3 & 0 & BW & 3.8/3.0 DFSa & n.s. \\
\hline Petersson et al. [2000] & 180 & $13-14$ & $\begin{array}{l}\geq 2 \text { proximal } \\
\text { lesions }\end{array}$ & $\mathrm{RCT}, \mathrm{SB}$ & 2 & $\mathrm{Fv}$ & 3 & 8 & BW & 3.1/2.7 DFSa & n.s. \\
\hline $\begin{array}{l}\text { Twetman and Petersson } \\
\text { [1999] }\end{array}$ & 174 & $8-10$ & $\geq 10^{5} \mathrm{CFU}$ & $\mathrm{CCT}, \mathrm{SB}$ & 2 & untreated & 2 & 2 & BW & $22 / 20 \% \mathrm{DFSa}$ & n.s. \\
\hline \multicolumn{12}{|l|}{ Fissures } \\
\hline Araujo et al. [2002] & 16 & $6-8$ & no & split & 2 & untreated & 2 & 0 & clin. + BW & $0 / 50 \%$ & $\mathrm{p}<0.01$ \\
\hline Baca et al. [2002] & 229 & $6-7$ & no & RCT SB & 2 & untreated & 2 & 21 & clin. & 0.9/1.8 DFSo & $\mathrm{p}<0.05$ \\
\hline Bratthall et al. [1995] & 502 & $5-12$ & no & split, SB & 2 & untreated & 2 & 16 & clin. & $7 / 16 \%$ & $\mathrm{p}<0.001$ \\
\hline Fennis-Ie et al. [1998] & 332 & $5-12$ & no & $\mathrm{RCT}, \mathrm{DB}$ & 3 & placebo & 3 & 5 & clin. & 0.6/0.6 DFSo & n.s. \\
\hline Joharji et al. [2001] & 200 & $7-14$ & no & split, SB & 2 & cleaning & 0.75 & 9 & clin. & $18 / 49 \%$ & $\mathrm{p}<0.001$ \\
\hline \multicolumn{12}{|l|}{ White spot lesions } \\
\hline Jenatschke et al. [2001] & 33 & $11-18$ & $\geq 10^{5} \mathrm{CFU}$ & RCT & 3 & placebo & debond. & 0 & clin. + BW & $31 / 32 \%$ & n.s. \\
\hline Øgaard et al. [2001] & 220 & $12-15$ & orthod. & RCT & $2+F v$ & $\mathrm{Fv}$ & debond. & 0 & clin. & $58 / 61 \%$ & \\
\hline Madlena et al. [2000] & 24 & $13-23$ & orthod. & split & 2 & placebo & debond. & 0 & clin. & $0.7 / 2.1 \mathrm{DS}$ & $\mathrm{p}<0.05$ \\
\hline Twetman et al. [1995] & 18 & $11-18$ & orthod. & split & 2 & placebo & debond. & 0 & clin. & $6 / 6 \%$ & n.s. \\
\hline \multicolumn{12}{|l|}{ Root caries } \\
\hline Banting et al. [2000] & 240 & $45-75$ & dry mouth & RCT; DB & 1 & placebo & 1 & 24 & clin. & $0.8 / 1.3$ & $\mathrm{p}<0.05$ \\
\hline Brailsford et al. [2002] & 134 & $70-80$ & frail elderly & $\mathrm{RCT}, \mathrm{DB}$ & $2+F v$ & placebo $+\mathrm{Fv}$ & 1 & 19 & clin. & $\begin{array}{l}42 / 30 \% \\
\text { improved }\end{array}$ & n.s. \\
\hline Powell et al. [1999] & 297 & $\geq 60$ & low income & RCT, SB & $\mathrm{R}$ & program & 3 & 32 & clin. & $23 \%$ reduction & n.s. \\
\hline
\end{tabular}

Intervention: 1 = Chlorzoin $(10 \%$ CHX, Oralife, Canada); $2=$ Cervitec $(1 \%$ CHX, Vivadent, Schaan, Liechtenstein); $3=$ EC-40 (40\% CHX, Explore Biodent $\mathrm{BV}$, Arnheim, the Netherlands); $\mathrm{R}=0.12 \% \mathrm{CHX}$ rinse; $\mathrm{Fg}=$ fluoride gel; $\mathrm{Fv}=$ fluoride varnish; outcome $=$ caries increment in test/control (mean values of surface or percentage of surfaces); $\mathrm{CFU}=$ colony-forming units of mutans streptococci per millilitre saliva; $\mathrm{RCT}=$ randomized clinical trial; $\mathrm{CCT}=$ controlled clinical trial; split = split-mouth; $\mathrm{DB}=$ double-blind; $\mathrm{SB}=$ single-blind; clin. = clinical examination; $\mathrm{BW}=$ bitewing radiographs; $\mathrm{n} . \mathrm{s}$. = not significant.

Table 2. Summary of recent studies with maternal antibacterial intervention with clinical caries as outcome measure in the mother's children

\begin{tabular}{|c|c|c|c|c|c|c|c|c|c|c|}
\hline Authors & Mothers & Risk & Design & Intervention & Time & Control & $\begin{array}{l}\text { Child } \\
\text { age } \\
\text { years }\end{array}$ & $\begin{array}{l}\text { Drop- } \\
\text { out, } \%\end{array}$ & Outcome & Statistics \\
\hline Dasanayake et al. [2002] & 75 & selected & RCT & CHX varnish & $6-36$ months $^{\mathrm{a}}$ & placebo & 4 & $?$ & $\mathrm{dft} 2.5 / 2.1$ & n.s. \\
\hline Günay et al. [1998] & 86 & selected & $\mathrm{CCT}$ & $\begin{array}{l}\text { CHX rinse + } \\
\text { varnish }^{\mathrm{b}}\end{array}$ & $\begin{array}{l}\text { 2nd trimester } \\
\text { to } 4 \text { years }\end{array}$ & untreated & 4 & 45 & dfs $1.5 / 7.0$ & $\mathrm{p}<0.001$ \\
\hline Isokangas et al. [2000] & 195 & $>10^{5} \mathrm{CFU}$ & RCT & $\mathrm{CHX}$ varnish & $3-24$ months $^{\mathrm{c}}$ & F varnish & 5 & 27 & $\mathrm{dmft} 3.2 / 2.9$ & n.s. \\
\hline
\end{tabular}

a 9 applications ( $10 \% \mathrm{CHX}$ varnish).

b CHX treatments as part of a comprehensive preventive programme.

c 3 applications (40\% CHX varnish). 
The reason could be that in frequent low-pH situations, the CHX-induced reduction of the sensitive bacteria may lead to an overgrowth of highly aciduric species such as MS and lactobacilli. It was therefore concluded that antibacterial treatments should always be accompanied by other preventive measures in caries-active children.

\section{Approximal Caries}

Four studies were identified in which only the approximal caries incidence in posterior teeth of caries-active schoolchildren was taken into account. The subjects were selected on the basis of having either proximal enamel lesions or elevated salivary bacterial counts. Two reports were 3-year CCTs with parallel arms in which CHX varnish or a mix of CHX and fluoride varnishes were tested against fluoride varnish applications in semi-annual or quarterly regimes [Petersson et al., 1998, 2000]. Caries incidence was determined from bitewing radiographs exposed with a film holder. Both studies were unable to unveil an additional caries-preventive effect of the CHX varnishes over the fluoride varnish alone. The other two papers were 2-year trials in schoolchildren, one with a split-mouth design [Haukali and Poulsen, 2003] and the other evaluated proximal caries incidence progression in relation to the degree of MS suppression [Twetman et al., 1999]. Both studies concluded that CHX varnish applications did not affect the overall proximal progression rate. In the latter study however, children who exhibited significantly suppressed MS counts after the treatments exhibited a lower incidence and progression rate compared with those with a less marked suppression. The results support previous findings that the outcome of the employed topical intervention must be monitored in order to decide whether or not to continue with further antibacterial treatments [Emilson, 1994].

\section{Fissure Caries}

Five studies were identified with fissure caries as end point [Bratthall et al., 1995; Fennis-Ie et al., 1998; Joharji and Adenubi, 2001; Araujo et al., 2002; Baca et al., 2002]. Three of the reports were split-mouth studies of first and second permanent molars in which a $1 \% \mathrm{CHX}$ /thymol varnish was applied 3 times per year versus untreated controls. The findings were all in favour of the antibacterial varnish, but it must be underlined that the investigations were carried out in subjects where the regular use of fluoride toothpaste or exposure to fluoride supplements was low or uncertain. Moreover, with one exception, the diagnosis of fissure caries was based on clinical examination only and without the aid of bitewing radiographs.
Two studies were RCTs in newly erupted first [Baca et al., 2002] and in first and second permanent molars [FennisIe et al., 1998]. Radiographs were not used. In the latter study, a 40\% CHX varnish was applied semi-annually for 3 years with a placebo varnish as control. The results disclosed no significant differences between the treatments when the entire study groups were taken into account. However, $15 \%$ of the children harboured high counts of salivary MS $\left(10^{6} \mathrm{CFU} / \mathrm{ml}\right.$ mixed saliva $)$ at baseline. In that subgroup, a post hoc statistical analysis indicated that the number of carious permanent molars was significantly reduced $(p<0.05)$ at the termination of the study. In the report by Baca et al. [2002], a CHX/thymol varnish was applied every third month for 2 years and the incidence of caries in the first molars was compared with that of untreated controls. A small but statistically significant reduction was disclosed, and the authors conclude that the antibacterial agent was a useful alternative to prevent fissure caries when appropriate dental facilities and resources were lacking. All papers explain the effectiveness of the varnish treatments in preventing fissure caries by the retentive nature of the occlusal surfaces, enabling a slow release of the antibacterial agent.

\section{White Spot Lesions}

Four studies dealing with early enamel lesion development were identified, all performed in patients undergoing treatment with fixed orthodontic appliances [Twetman et al., 1995; Madlena et al., 2000; Jenatschke et al., 2001; Øgaard et al., 2001]. Insertion of appliances may interfere with oral hygiene procedures, resulting in plaque accumulation and an increased risk for "white spot lesions' adjacent to the luted bands or bonded bracket bases. Two studies were very small and utilized a splitmouth design with $\mathrm{CHX}$ varnish versus a placebo varnish applied during the time of active treatment. Conflicting results were reported. Madlena et al. [2000] found a significant reduction of white spot lesions following CHX varnish treatments among children with a higher caries increment while no effect could be found in a Swedish low-caries population [Twetman et al., 1995]. The two most recent investigations were RCTs comparing CHX varnish with placebo or fluoride varnish as controls [Jenatschke et al., 2001; Øgaard et al., 2001]. In the former study, the orthodontic patients were screened and recruited with high counts of salivary MS while the other included 220 non-selected cases with varying levels of MS. Both studies were unable to disclose any benefit from frequent $\mathrm{CHX}$ varnish applications on white spot lesion development during treatment with fixed orthodontic ap- 
pliances, in spite of significant reductions in MS colonization.

\section{Root Caries}

Three papers dealt with CHX treatments and root caries development in elderly and low-income older adults [Powell et al., 1999], dry-mouth risk patients [Banting et al., 2000] and in frail institutionalized people [Brailsford et al., 2002]. Powell et al. [1999] demonstrated a nonsignificant reduction of root caries events following weekly $0.12 \% \mathrm{CHX}$ rinses and fluoride varnish compared with a group receiving 'usual' care from private practitioners. The other studies were 1-year placebo-controlled randomized trials, and one of them demonstrated a significant reduction and control of root caries lesions, suggesting regular antibacterial applications to be beneficial for these patient groups [Banting et al., 2000]. Notably, neither Powell et al. [1999] nor Banting et al. [2000] found any significant impact on coronal caries increment, but to be fully conclusive on this matter, increased size of study groups and prolonged duration would have been desirable. The results of the root caries studies may however indicate that the antimicrobial therapy may act differently for lesions and cavities located in dentine and enamel, respectively.

\section{Mother-Child Transmission}

The primary preventive concept to interfere with the mother-child transmission route of MS has gained continuous interest during the recent decades. The 'classic' studies by Köhler et al. [1984] and Tenovuo et al. [1992] clearly showed that CHX gel treatments of highly infected mothers could reduce MS colonization and caries development in their children. Since then, a number of additional papers on this issue have been presented [Brambilla et al., 1998; Söderling et al., 2000; Gripp and Schlagenhauf, 2002; Thorild et al., 2003], but only three have reported caries as end point. These studies are compiled in table 2. In a German study, Günay et al. [1998] offered a comprehensive preventive programme for mothers and children that started during pregnancy and continued for 4 years. The programme, which included CHX-containing rinses and varnishes, resulted in significantly improved oral health for both the mothers and their children, but the role of the antibacterial agents could not be distinguished from the other measures within the programme. Isokangas et al. [2000] focused mainly on xylitol but included treatments with either CHX- or fluoridecontaining varnishes of highly colonized mothers as controls. The mothers were treated on 3 occasions, when their children were 6,12 and 18 months of age, but no differences in caries increment up to 5 years of age were noticed between the CHX and fluoride varnish groups. Recently, Dasanayake et al. [2002] have published a placebo-controlled RCT in which they evaluated the efficacy of CHX varnish treatments of mothers during the eruption of their children's first teeth and during the second year of life. Although a significant reduction of MS levels in both mothers and children could be seen, no effect on caries development was found among the children. Thus, topical applications of antibacterial agents may reduce the transmissions of oral MS from host to host, but this does not necessarily result in less caries. This approach merits to be further elucidated in terms of effectiveness and efficiency.

\section{Other Antibacterial Agents of Clinical Interest}

Triclosan is a broad-spectrum biocide that may affect many types of oral bacteria. The agent has been incorporated into dentifrices together with a copolymer, and reductions in supragingival plaque and gingivitis have been claimed [Gaffar et al., 1997]. A number of cariesfocused RCTs with triclosan/copolymer-containing fluoride toothpastes have been carried out in schoolchildren and adults [Hawley et al., 1995; Feller et al, 1996; Mann et al., 1996]. The results clearly showed that the addition of the antibacterial agent neither compromised nor enhanced the anticaries effect of the toothpaste. However, in a recent study from Israel, the effect of unsupervised tooth brushing with two $0.243 \%$ sodium fluoride dentifrices with and without $0.3 \%$ triclosan and $2 \%$ copolymer on coronal caries was evaluated in adults [Mann et al., 2001]. The 2-year findings were significantly in favour of the dentifrice with triclosan, indicating an additional anticaries effect that should be further investigated.

The antibacterial properties of povidone-iodine as a mucosal antiseptic in medicine are well established, but the agent is rarely utilized in dentistry. Povidone-iodine is water soluble and non-irritating and exhibits no adverse effects such as discoloration and taste alterations, but iodine hypersensitivity, thyroid pathosis and pregnancy are contra-indications. The efficacy of a $10 \%$ povidoneiodine solution to prevent early childhood caries has recently been evaluated in a randomized double-blind placebo-controlled trial [Lopez et al., 2002]. The results showed that this topical antimicrobial therapy increased the time of 'disease-free survival' in toddlers with high risk of early caries development. 


\section{Future Perspectives for Research}

Despite the recent decline, caries is still the most prevalent dental infectious disease with a giant unmet treatment need in many countries. A general concern is that the dental practitioner is still treating caries with a surgical approach rather than with prevention or pharmacotherapeutics. An urgent task for the scientific community is therefore to initiate clinical studies to confirm the efficacy and safety of non-surgical treatment of caries with focus both on the population and selected patient groups. It is not only a question of performing more investigations but also better ones. Well-designed multi-centre trials with antibacterial intervention according to a standard protocol would be desirable, and special efforts should be made to select representative study groups with enough power to ensure firm conclusions. Future research must also be extended to incorporate preschoolers, adults and elderly subjects. No studies can be designed without regular exposure of fluoride from toothpastes or any other commonly used alternative non-surgical treatment for ethical reasons. Since the existing antibacterial agents seem to be less effective for the caries-active patients with the highest need, more potent and long-lasting drugs with as few side-effects as possible need to be developed. In order to improve efficiency and compliance, it seems reasonable in the future to move from topical administrations by professionals to consumer products and homecare procedures, such as antibacterial constituents incorporated into dentifrices and chewing gums. The early intervention concept is interesting as it may be easier to affect the caries-associated bacteria before their perma- nent colonization compared to later in life when the resident oral flora is firmly established [Könönen, 2000]. The screening of mothers and potentially long treatment duration are however drawbacks in terms of cost and compliance. A full-scale investigation at the population level, including both parents, would be a project of high priority.

It may very well be that antibacterial agents are underutilized and factors such as dentist's knowledge and attitudes, poor patient compliance and low willingness to pay may likely play a role. In today's evidence-based care, also the patient's wishes and demands must be taken into account. Therefore, qualitative studies should be planned and undertaken parallel with, and linked to the intervention protocol in order to unveil the patient's thinking. Further, studies on how to communicate the preventive health message and increase motivation in caries risk patients and vulnerable groups should be encouraged.

\section{Conclusions}

The evidence for an anticaries effect of CHX-containing varnishes was rated as inconclusive for caries-active schoolchildren and adolescents with daily exposure to fluoride as well as for root caries arrest in elderly subjects. It must however be underlined that 'inconclusive evidence of effect' is not the same as 'evidence of no effect' in the sense that antibacterial methods are of no value and should be abandoned. It is however definitely a call for further research and development of well-designed studies.

\section{References}

Anderson MH: A review of the efficacy of chlorhexidine on dental caries and the caries infection. $J$ Calif Dent Assoc 2003;31:211-214.

Araujo AMPG, Naspitz GMCC, Chelotti A, Cai S Effect of Cervitec ${ }^{\circledR}$ on mutans streptococci in plaque and caries formation on occlusal fissures of erupting permanent molars. Caries Res 2002;36:373-376.

Baca P, Munoz MJ, Bravo M, Junco P, Baca AP Effectiveness of chlorhexidine-thymol varnish for caries reduction in permanent first molars of 6-7-year-old children: 24-month clinica trial. Community Dent Oral Epidemiol 2002, 30:363-368.
Banting DW, Papas A, Clark DC, Proskin HM, Schultz M, Perry R: The effectiveness of $10 \%$ chlorhexidine varnish treatment on dental caries incidence in adults with dry mouth. Gerodontology 2000;17:67-76.

Brailsford SR, Fiske J, Gilbert S, Clark D, Beighton D: The effects of the combination of chlorhexidine/thymol- and fluoride-containing varnishes on the severity of root caries lesion in frail institutionalised elderly people. J Dent 2002;30:319-324.

Brambilla E, Felloni A, Gagliani M, Malerba A, Garcia-Godoy F, Strohmenger L: Caries prevention during pregnancy: Results of a 30month study. J Am Dent Assoc 1998;129:871877.
Bratthall D, Serinirach R, Rapisuwon S, Kuratana M, Luangjarmekorn, Luksila K, Chaipanich P: A study into the prevention of fissure caries using antimicrobial varnishes. Int Dent J 1995; 45:245-254.

Britton M: Så graderas en studies vetenskapliga bevisvärde och slutsatsernas styrka. Läkartidningen 2000;97:4414-4415.

ten Cate JM: Current concepts on the theories of action of fluoride. Acta Odontol Scand 1999; 73:325-329.

Caufield PW, Dasanayake AP, Li Y: The antimicrobial approach to caries management. J Dent Educ 2001;65:1091-1095. 
Dasanayake AP, Wiener HW, Li Y, Vermund SV, Caufield PW: Lack of effect of chlorhexidine varnish on Streptococcus mutans transmission and caries in mothers and children. Caries Res 2002;36:288-293.

Emilson CG: Potential efficacy of chlorhexidine against mutans streptococci and human dental caries. J Dent Res 1994;73:682-691.

Feller RP, Kiger RD, Triol CW, Sintes JL, Garcia L, Petrone ME, Volpe AR, Proskin HM: Comparison of the clinical anticaries efficacy of an 1,100 NaF silica-based dentifrice containing triclosan and a copolymer to an $1,100 \mathrm{NaF}$ silica-based dentifrice without those additional agents: A study on adults in California. J Clin Dent 1996; 7:85-89.

Fennis-Ie YL, Verdonschot EH, Burgersdijk RCW, König KG, van't Hof MA: Effect of 6-monthly applications of chlorhexidine varnish on incidence of occlusal caries in permanent molars. $\mathrm{J}$ Dent 1998;26:233-238.

Forgie AH, Paterson M, Pine CM, Pitts NB, Nugent $\mathrm{ZJ}$ : A randomised controlled trial of the caries-preventive efficacy of a chlorhexidinecontaining varnish in high-caries-risk adolescents. Caries Res 2000;34:432-439.

Gaffar A, Afflitto J, Nabi N: Chemical agents for the control of plaque and plaque microflora. Eur J Oral Sci 1997;105:502-507.

Gripp VC, Schlagenhauf U: Prevention of early mutans streptococci transmission in infants by professional tooth cleaning and chlorhexidine varnish treatment of the mother. Caries Res 2002;36:366-372

Günay H, Dmoch-Bockhorn K, Günay Y, Geurtsen W: Effect on caries experience of a longterm preventive program for mothers and children starting during pregnancy. Clin Oral Invest 1998:2:137-142.

Haukali G, Poulsen S: Effect of a varnish containing chlorhexidine and thymol $\left(\right.$ Cervitec $\left.^{\circledR}\right)$ on approximal caries in 13- to 16-year-old schoolchildren in a low caries area. Caries Res 2003 37:185-189.

Hawley GM, Hamilton FA, Worthington HV, Davies RM, Holloway PJ, Davies TG, Blinkhorn AS: A 30-month study investigating the effect of adding triclosan/copolymer to a fluoride dentifrice. Caries Res 1995;29:163-167.

van Houte J: Role of microorganisms in caries etiology. J Dent Res 1994;73:672-681.

Isokangas P, Söderling E, Pienihäkkinen K, Alanen $P$ : Occurrence of dental decay in children afte maternal consumption of a xylitol chewing gum, a follow-up from 0 to 5 years of age. $\mathrm{J}$ Dent Res 2000;79:1885-1889.
Jenatschke F, Elsenberger E, Welte HD, Schlagenhauf U: Influence of repeated chlorhexidine varnish applications on mutans streptococci counts and caries increment in patients treated with fixed orthodontic appliances. J Orofac Orthop 2001;62:36-45.

Joharji RM, Adenubi JO: Prevention of pit and fissure caries using antimicrobial varnish: 9month clinical evaluation. J Dent 2001;29: 247-254.

Kidd EAM: Role of chlorhexidine in the management of dental caries. Int Dent J 1991;41:279286.

Köhler B, Andreen I, Jonsson B: The effect of caries-preventive measures in mothers on dental caries and the oral presence of the bacteria Streptococcus mutans and lactobacilli in their children. Arch Oral Biol 1984;29:879-883.

Könönen E: Development of oral bacterial flora in young children. Ann Med 2000;32:107-112.

Lopez L, Berkowitz R, Spiekerman C, Weinstein P: Topical antibacterial therapy in the prevention of early childhood caries: A follow-up report. Pediatr Dent 2002;24:204-206.

Madlena M, Vitalyos G, Marton S, Nagy G: Effect of chlorhexidine varnish on bacterial levels in plaque and saliva during orthodontic treatment. J Clin Dent 2000;11:42-46.

Mann J, Karniel C, Triol CW, Sintes JL, Garcia L, Petrone ME, Volpe AR, Proskin HM: Comparison of the clinical anticaries efficacy of an 1,500 NaF silica-based dentifrice containing triclosan and a copolymer to an 1,500 NaF silica-based dentifrice without those additional agents: A study on adults in Israel. J Clin Dent 1996; 7:90-95.

Mann J, Vered Y, Babayof I, Sintes J, Petrone ME, Volpe AR, Stewart B, De Vizio W, McCool JJ, Proskin HM: The comparative anticaries efficacy of a dentifrice containing $0.3 \%$ triclosan and $2 \%$ copolymer in a $0.243 \%$ sodium fluoride/silica base and a dentifrice containing $0.243 \%$ sodium fluoride/silica base: A two-year coronal caries clinical trial on adults in Israel. $\mathrm{J}$ Clin Dent 2001;12:71-76.

Marsh PD: Microbial ecology of dental plaque and its significance in health and disease. Adv Dent Res 1994;8:263-271.

Marsh PD: Are dental diseases examples of ecological catastrophes? Microbiology 2003;149:279_ 294.

Matthijs S, Adriaens PA: Chlorhexidine varnishes: A review. J Clin Periodontol 2002;29:1-8.

Øgaard B, Larsson E, Henriksson T, Birkhed D, Bishara SE: Effects of combined application of antimicrobial and fluoride varnishes in orthodontic patients. Am J Orthod Dentofac Orthop 2001;120:28-35.
Petersson LG, Magnusson K, Andersson H, Almquist B, Twetman S: Effect of quarterly treatments with a chlorhexidine and a fluoride varnish on approximal caries in caries-susceptible teenagers: A 3-year clinical study. Caries Res 2000;34:140-144.

Petersson LG, Magnusson K, Andersson H, Deierborg G, Twetman S: Effect of semi-annual applications of a chlorhexidine/fluoride varnish mixture on approximal caries incidence in schoolchildren: A three-year radiographic study. Eur J Oral Sci 1998;106:623-627.

Powell LV, Persson RE, Kiyak HA, Hujoel PP: Caries prevention in a community-dwelling older population. Caries Res 1999;33:333339.

van Rijkom HM, Truin GJ, van't Hof MA: A metaanalysis of clinical studies on the caries-inhibiting effect of chlorhexidine treatment. J Dent Res 1996;75:790-795.

Rozier RG: Effectiveness of methods used by dental professionals for the primary prevention of dental caries. J Dent Educ 2001;65:10631072.

Söderling E, Isokangas P, Pienihäkkinien K, Tenovuo J: Influence of maternal xylitol consumption on acquisition of mutans streptococci by infants. J Dent Res 2000;79:882-887.

de Soet JJ, Gruythuysen RJM, Bosch JA, van Amerongen WE: The effect of 6-monthly application of $40 \%$ chlorhexidine varnish on the microflora and dental caries incidence in a population of children in Surinam. Caries Res 2002; 36:449-455.

Splieth C, Steffen H, Rosin M, Welk A: Caries prevention with chlorhexidine-thymol varnish in high risk schoolchildren. Community Dent Oral Epidemiol 2000;28:419-423.

Tenovuo J, Häkkinen P, Paunio P, Emilson CG: Effects of chlorhexidine-fluoride gel treatments in mothers on the establishment of mutans streptococci in primary teeth and the development of dental caries in children. Caries Res 1992;26:275-280.

Thorild I, Lindau B, Twetman S: Effect of maternal use of chewing gums containing xylitol, chlorhexidine or fluoride on mutans streptococci colonization in the mother's infant. Oral Health Prev Dent 2003; 1:53-57.

Twetman S, Hallgren A, Petersson LG: Effect of an antimicrobial varnish on mutans streptococci in plaque from enamel adjacent to orthodontic appliances. Caries Res 1995;29:188-191.

Twetman S, Petersson LG: Interdental caries incidence and progression in relation to mutans streptococci suppression after chlorhexidinethymol varnish treatments in schoolchildren. Acta Odontol Scand 1999;57:144-148. 